\title{
THE COVID-19 VACCINATION AGENDA. EUROPEAN AND PORTUGUESE OFFICIAL SOURCES' PERFORMANCE IN FACEBOOK, INSTAGRAM, TWITTER AND LINKEDIN
}

\section{CLARA ALMEIDA SANTOS}

clara.santos@uc.pt

Assistant Professor at the Department of Philosophy, Communication and Information of the Faculty of Letters of the University of Coimbra (Portugal) and integrated researcher in CEIS20 -

Centre for Interdisciplinary Studies.

OLGA ESTRELA MAGALHÃES

olgamagalhaes@med.up.pt

Coordinator of the Communication and Image Office of the Faculty of Medicine of the University of Porto (Portugal) and researcher at CINTESIS - Health Technologies and Services Research

Centre.

CATARINA DUFF BURNAY

cburnay@ucp.pt

Associate Professor at FCH/UCP (Portugal), Coordinator of the Masters in Communication Sciences and researcher at the Centre for Communication and Culture Studies (CECC).

RITA ARAÚJO

rita.manso.araujo@gmail.com

Researcher at CECS - Centre for Communication and Society Studies, University of Minho, Institute of Social Sciences (Portugal).

Abstract

The authorization for the vaccine against Covid-19 and the beginning of the vaccination in the European Union represent a very singular moment in several dimensions, including strategic communication. In the context of a pandemic and an infodemic - an epidemic also recognized by the World Health Organization (WHO) characterized by the abnormal increase of information on a given subject carrying the risk of severe disinformation phenomena - the need for authorities (both Portuguese and European) to convey accurate information and to maintain a communicative proximity is crucial. In these circumstances, online social networks represent ineluctable channels to deliver official information. In this article, we analyze how the European Commission, the European Medicines Agency (EMA), the WHO Regional Office for Europe, the European Centre for Disease Prevention and Control, the Representation of the European Commission in Portugal, the Portuguese Government, the Portuguese Directorate-General of Health, and the Portuguese National Health Service have used Facebook, Instagram, Twitter and LinkedIn to communicate the vaccination during one month since the EMA's authorization (21st December 2020). All posts from the referred sources on the four social networks (719 occurrences) were collected and content analysis methods were then applied. The results show that both Portuguese and European official sources use social media to convey authoritative information about the vaccination against Covid-19: more than one third of the posts analyzed link to institutional websites and more than half the publications have an informative framing. On the other hand, the analyze suggests that there is a strong political capitalization of the momentum of hope. This exploratory study case shows the importance of social media analysis in the context of the Covid-19

\section{Keywords}

Covid-19; Vaccination; social media; Disinformation; European Union

How to cite this article

Santos, Clara A.; Magalhães, Olga E.; Burnay, Catarina D.; Araújo, Rita. The COVID-19 vaccination agenda. European and portuguese official sources' performance in facebook, Instagram, Twitter and Linkedin. Thematic dossier International Relations and Social Networks, July 2021. Consulted [online] on date of last visit, https://doi.org/10.26619/16477251.DT21.11 


\section{THE COVID-19 VACCINATION AGENDA. EUROPEAN AND PORTUGUESE OFFICIAL SOURCES' PERFORMANCE IN FACEBOOK, INSTAGRAM, TWITTER AND LINKEDIN ${ }^{1}$}

CLARA ALMEIDA SANTOS

OLGA ESTRELA MAGALHÃES

CATARINA DUFF BURNAY

RITA ARAÚJO

\section{Introduction}

It was quite surprising when European Commissioner Thierry Breton, in May 2020, speaking on a debate promoted by the Regulation Center in Europe, said that disinformation was "the disease of the century". In the midst of the Covid-19 pandemic, the statement was likely to sound misfit, to say the least. Nevertheless, we can be quite sure that we are globally dealing with a syndemic, a concept developed by Merrill Singer (2009) that refers to complex epidemics implying disease interactions. Along with and fueled by Covid-19, an infodemic has developed worldwide. Coincidentally enough, the term "infodemic" was coined by David Rothkopf in $2003^{2}$ in relation to the flood of information accompanying the SARS-CoV-1 (the "first" coronavirus) outbreak. An infodemic, as defined by the World Health Organisation (WHO), is an "overabundance of information - some accurate and some not - that occurs during an epidemic. It can lead to confusion and ultimately mistrust in governments and public health response ${ }^{\prime \prime 3}$. The dimension of this infodemic (and consequent syndemic, according to Santos et al, 2021) is amplified by the unprecedented massive use of technology and social media. Researchers (eg Cinelli et al, 2020) are using variants of standard epidemic models to simulate the spreading of information on social media.

In fact, one of the fundamental dimensions of this global crisis is digital dependence. Digitalization and digitization made it possible to overcome many of the restrictions the world had to face. Lockdowns obviously increased the time spent online and changed

\footnotetext{
Article translated by the autors and reviewed by Carolina Peralta.

https://www.washingtonpost.com/archive/opinions/2003/05/11/when-the-buzz-bites-back/bc8cd84fcab6-4648-bf58-0277261af6cd, accessed January 212021.

3 https://www.who.int/teams/risk-communication/infodemic-management, accessed January 212021.
} 
digital habits. According to the Reuters Institute Digital News Report 2020, and not surprisingly, the use of online and social media substantially increased in most countries. In this aspect (as in others) the Coronavirus disease is unprecedented: it is "the first pandemic in history in which technology and social media are being used on a massive scale to keep people safe, informed, productive and connected. At the same time, the technology we rely on to keep connected and informed is enabling and amplifying an infodemic that continues to undermine the global response and jeopardizes measures to control the pandemic ${ }^{\prime 4}$. In early May 2020, the European Commission registered daily more than 2.700 articles with "fake news" related to Covid-19 on social networks, including false or misleading publications.

In October 2018, several platforms and companies - including Facebook, Twitter, Google and Mozilla - signed a "Code of Practice", under the umbrella of the European Commission, that includes a wide range of commitments to fight online disinformation. Since then, the signatories have been producing periodic self-assessment reports on the measures undertaken "from transparency in political advertising to the closure of fake accounts and demonetisation of purveyors of disinformation" ${ }^{\prime 5}$. The declared aim is to "contribute to a fast and measurable reduction of online disinformation"

According to the report from Facebook for December $2020^{7}$, over 401 thousand pieces of content on Facebook and Instagram were removed for containing misinformation that might lead to imminent physical harm, such as content relating to fake preventative measures or exaggerated cure, and 40 thousand pieces of content related to Covid-19 and which violated the platform medical supply sales standards.

The war against infodemy is particularly relevant to prevent and control the effects of the syndemic. As Josep Borrell, Vice-President of the European Commission put it: "Disinformation in times of the coronavirus can kill. We have a duty to protect our citizens by making them aware of false information and expose the actors responsible for engaging in such practices" ${ }^{\prime \prime}$.

\section{1. "Information disorder"}

Following UNESCO's recommendations (Ireton and Posetti, 2018), we will not use the popular term "fake news" to refer to information disorders. Wardle and Derakhshan (2017) dismiss the utilization of this expression for two reasons: on the one hand, because it has been used by politicians to describe news coverage that they find "disagreeable"; on the other hand, because they find that it is "woefully inadequate to describe the complex phenomena of information pollution" (Wardle and Derakhshan, 2017: 5). In plus, as several other authors point out, the term "news" presumptions information that is delivered after a process of professional verification - which is not the case for "fake news". The referred authors coined the expression "information disorder"

4 https://www.who.int/news/item/23-09-2020-managing-the-covid-19-infodemic-promoting-healthybehaviours-and-mitigating-the-harm-from-misinformation-and-disinformation, accessed January 212021.

https://ec.europa.eu/commission/presscorner/detail/en/STATEMENT 18 5914, accessed February 32021. $\underline{\text { Idem }}$

7 https://ec.europa.eu/digital-single-market/en/news/latest-set-reports-and-way-forward-fighting-covid19-disinformation-monitoring-programme, accessed January 202021.

8 https://ec.europa.eu/commission/presscorner/detail/en/ip $20 \quad 1006$, accessed February 32021. 


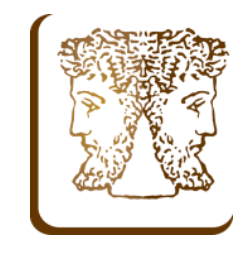

to describe a much more complex phenomenon considering two dimensions: falsity and intention. "Information disorder" includes three types of "toxic" information: misinformation, disinformation and mal-information. Misinformation and disinformation are both characterized by falseness. The difference according to Wardle and Derakhshan is that misinformation has no intention to harm while disinformation is conveyed with malicious intentions. Disinformation might include different forms of willingly forged content and context, as shown in Figure 1.

Figure 1. Concepts of misinformation, disinformation and mal-information

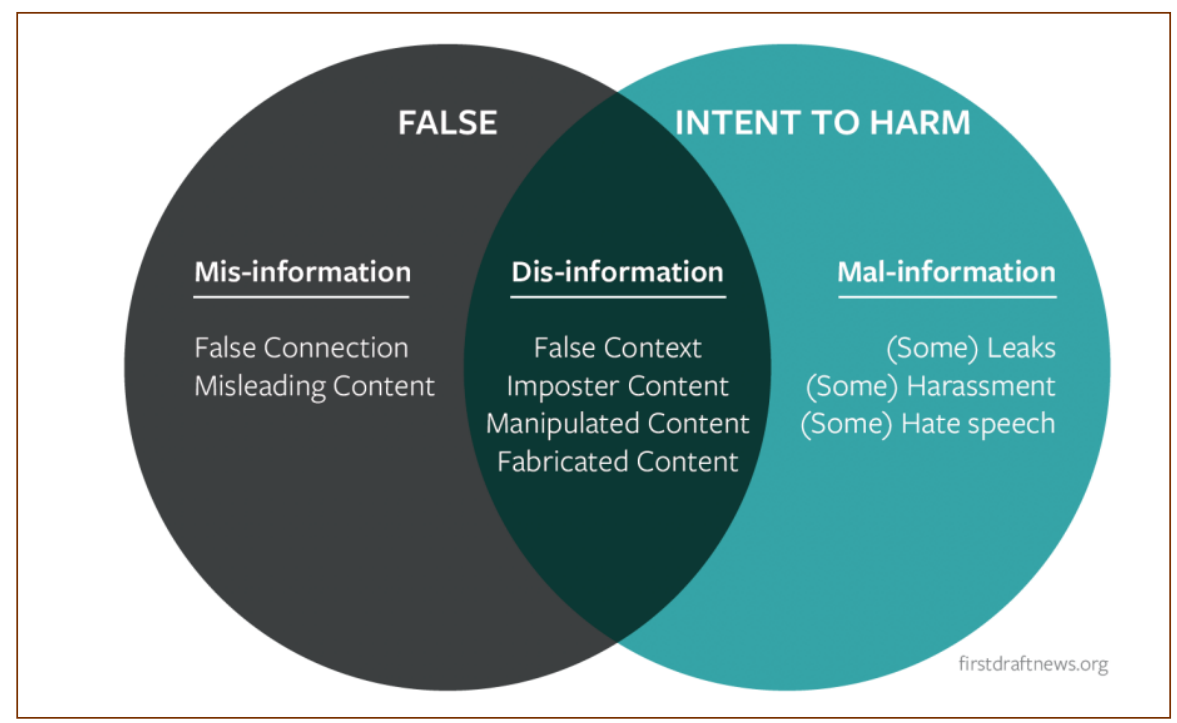

Source: Ireton and Posetti (2018).

Mal-information though mischiefing, is based on reality. True facts or partially truthful facts are used but in most of the cases, it is not the whole story and the narrative is purposefully used to "inflict harm on a person, organisation or country" (Wardle and Derakhshan, 2017: 46).

In the Covid-19 syndemic context, the information disorder combined with the already referred unprecedented usage of social media create an humungous challenge for authorities that need to keep the population accurately informed about the virus and the disease and to disseminate important health messages. Previous epidemic crisis during the 21st century have shown how harmful and even lethal the information disorder can be (eg Oyeyemi, Gabarron, Wynn, 2014, Knobler et al, 2004). It adds up that given the uncertainty in much that is related to the virus and the disease, "distorted versions of concepts and scientific facts proliferate, employing extraordinarily plausible narrative and rhetorical forms that flourish in the midst of the scarcity of contents recommending biosafety practices during a pandemic" (Vasconcellos-Silva and Castiel, 2020: 2). The same authors claim that fact-twisting - emerging as misinfomation, desinformation or mal-information - proliferates in the absence of the official narrative. As the WHO puts it in the context of the 1st WHO Infodemiology Conference, held on June and July 2020, "like pathogens in epidemics, misinformation spreads further and faster and adds 
complexity to health emergency response" ${ }^{\prime \prime}$. The WHO recognizes the difficulty to find trustworthy sources and reliable guidance. And "even when people have access to highquality information, there are still barriers they must overcome to take the recommended action"10.

The usage of social media by governments and other official entities can be regarded as part of evolving practices of digital governance. As Magro (2012) underlines after analysing several case studies, using social media in disaster management is an important role for governments. According to Dadashzadeh (2010), using social media in governance might prompt many benefits such as: improving social and economic conditions of citizens, providing access, engaging, and educating all citizens, improving Government accountability by increased transparency, or improving te effectiveness of initiatives and providing citizens the opportunity to "talk back".

\subsection{Health communication: the Covid-19 vaccination campaign}

The vaccination campaign against Covid-19 that started in every member state of the European Union (EU) on the 27th December 2020 represents a very singular moment in several aspects. Firstly, because of its institutional, concerted, transnational, political and scientific character as a response to "the most formidable challenge to humanity in a century" (Jeyanathan et al, 2020). As far as communication is concerned, a vaccination campaign occurring in the midst of the pandemic and infodemic increases drastically the need for official sources to disseminate accurate and reliable information. Vaccination is actually the theme of one of the most well-known case studies on the effects of information disorder. In 1998 Andrew Wakefield published an article in the prestigious medical journal The Lancet that linked mumps, measles, and rubella (MMR) vaccine and autism. The journal eventually retracted the paper in 2010 because the findings were discredited but its message had already reached many people (Arif et al, 2020) namely through subsequent news. Online, both information and information disorders remain (and remain). As the referred authors conclude, counteracting disinformation about vaccines by health authorities is part of the solution. Political and health authorities face many challenges as current public health communications about vaccines may not be effective and may, in fact, "increase misperceptions or reduce vaccination intention" (Nyhan et al 2014: 2013). The authors claim that more studies of pro-vaccine messaging are needed, and that vaccination messaging should be carefully tested before making it public.

A study conducted by Neumann-Böhme et al (2020) has shown the willingness of Europeans from seven countries (Denmark, France, Germany, Italy, Portugal, the Netherlands, and the UK) to be vaccinated against Covid-19. The results show that $73.9 \%$ of the 7664 participants stated that they would be willing to get vaccinated. The willingness ranged from $62 \%$ in France to approximately $80 \%$ in Denmark and the UK. Only $7.2 \%$ stated that they do not want to get vaccinated. France, Portugal and Germany present the highest rate of respondents that stated their uncertainty towards the vaccine.

9 https://www.who.int/news-room/events/detail/2020/06/30/default-calendar/1st-who-infodemiologyconference, accessed on January 202021.

10 Idem. 
When asked about the reasons for being unsure, more than half $(55 \%)$ said they were concerned about potential side effects of a vaccine. Around $15 \%$ of respondents stated concern about the vaccine safeness.

Figure 2: Willingness to be vaccinated against the coronavirus by country

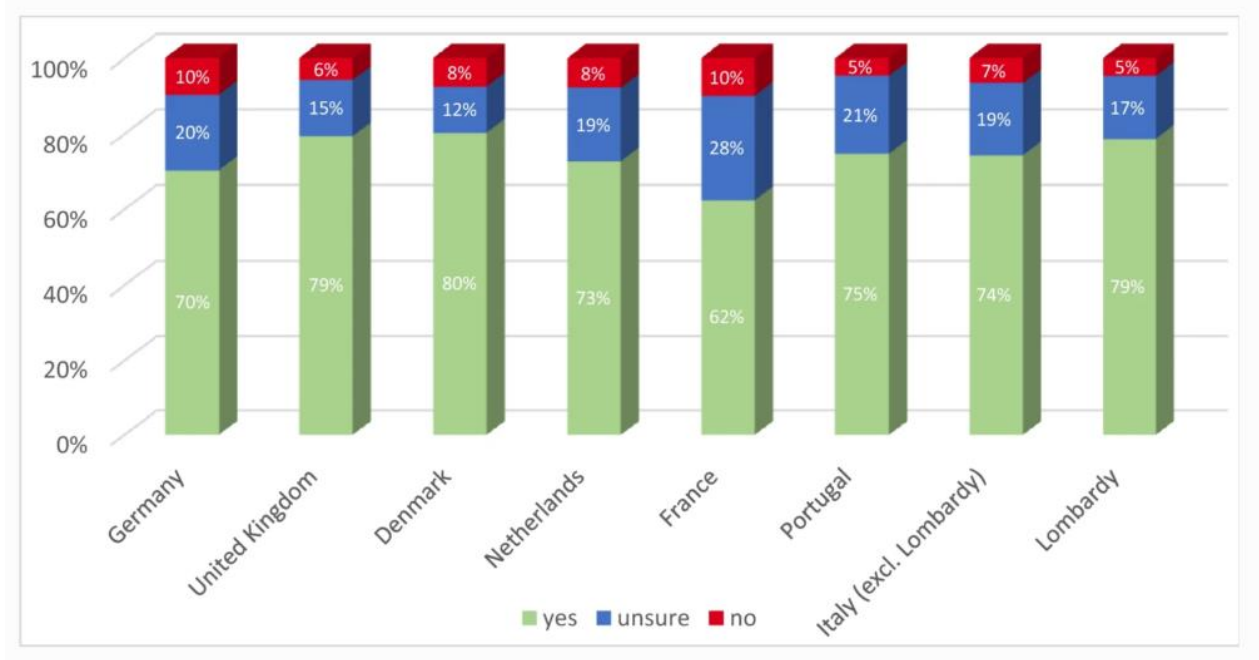

Source: Neumann-Böhme et al (2020)

In this context, it is crucial to recognize the importance of health communication, which has emerged as one of the most important public health issues in this century (Ishikawa and Kiuchi, 2010). Furthermore, several authors agree that it is a key factor in fighting the Covid-19 pandemic (Finset et al, 2020, Fielding, 2020). Indeed, he sudden appearance of SARS-CoV-2 has highlighted the importance of health communication and health literacy within infectious diseases, and the constant evolution of the virus and the science surrounding it makes people seek health information in order to adapt their behaviors (Paakari and Okan, 2020), see their questions answered, and limit transmission.

Therefore, it comes as no surprise that the infodemic surrounding Covid-19 "poses a serious problem for public health" (Zarocostas, 2020), since an adequate level of health literacy is required to deal with both misinformation and disinformation. In that sense, the Covid-19 pandemic has brought to light the underestimated public health problem of low health literacy (Paakari and Okan, 2020). Indeed, "providing the population with evidence-based scientific data is beneficial and necessary but does not necessarily lead to individuals correctly understanding or interpreting the information" (Biasio et al, 2020). Several studies recognize the importance of health literacy as a determinant of health outcomes and a driver of unnecessary costs (Parker and Ratzan, 2010; Berkman et al, 2010; Paasche-Orlow and Wolf, 2010), as well as pointing out the association between literacy skills and the engagement in health-related decisions, such as the management of a chronic disease or the compliance with health-promoting and diseasepreventive behaviors (Rudd et al, 2012, Zarcadoolas et al, 2006). Vaccination is one of those disease-preventive behaviors that can be seriously affected by low health literacy 
levels, along with dis- and misinformation. Vaccine hesitancy - the reluctance or refusal to vaccinate despite the availability of vaccines - is recognized by the $\mathrm{WHO}^{11}$ as a major threat to global health. Moreover, the rapid production of Covid-19 vaccines and all the information surrounding vaccine development and implementation as well as safety and efficacy may be challenging for individuals to gather and process (Vanderpool et al, 2020).

Hence, news media play a central role in the promotion of health since they are often the primary source of information to the lay public. During a public health crisis people depend on the news media to convey accurate and up-to-date information that allows them to make informed health decisions. Equally important is "training scientists and government agencies to discuss in plain language the benefits of a future Covid-19 vaccine with the media" (Schiavo, 2020: 74). The medical-scientific language is one of the problems traditionally identified by journalists in health and science communication and all strategies that can improve the individual skills of sources to communicate with different audiences, including journalists, are welcome. Therefore, the intervention and expertise of communication professionals, who understand the media routines and master efficient health communication strategies, is very important (Magalhães, 2020).

Health authorities and political leaders are responsible for mitigating the potential information disorder around the vaccination through communication. Social media provide the possibility to communicate in a "disintermediated environment" (Vicario et al, 2016), the exact same environment that can foster confusion, encourage mistrust and allow communicative proximity, and convey accurate and authoritative information.

The vaccination campaign in the UE provides a precious momentum to analyze how official sources use social media to encourage vaccination, to dismiss doubts and apprehension about the safety of the vaccines and to disseminate reliable facts counteracting against possible information disorders.

\section{Research design and methodology}

Social media are in contemporary communication dynamics the main vehicles of disinformation, misinformation and mal-information (Newman et al, 2020). Fracturing themes become permeable to the instantaneous construction and rapid dissemination of conspiracy theories and little grounded perspectives, motivating, in the context of a pandemic like Covid-19, over and under reactions (Pennycook et al, 2020). These reactions call into question the safety of the individual, but in this specific case, the safety of the community itself, making it difficult to control the disease and its global effects. In a joint and global effort, strategies have been developed to combat the proliferation of false or distorted news around Covid-19 from a communication/journalistic and legal point of view, as also by the social media platforms, showing themselves to be more aggressive than they were on political topics (Radu, 2020, Nunziato, 2020).

According to Reuters Digital News Report 2020, Portugal, along with Finland, is the country, out of 40 analysed, that trusts the news the most, but less than 3 out of 10

11 https://www.who.int/news-room/spotlight/ten-threats-to-global-health-in-2019, accessed on_January 18 th 2021. 
Portuguese say they trust news spread by social media and three quarters of the sample shows concern about the legitimacy of online content. If Facebook is the main network for news consumption (50.2\%), it is interesting to see how in a pandemic context instant messaging apps (eg Whatsapp) have gained relevance, boosting the dissemination of disinformation (Cardoso et al, 2020). At the same time, because of their reach and spreadability potential, social media are also powerful weapons to fight back against information disorders, playing an important role in policy announcement and health education (Tsao et al, 2021), allowing sources to deliver authoritative information directly to the receivers. In this sense, the use of social media by official sources as a vehicle of excellence to reach a wide and widespread audience has grown, showing itself as a potential step towards dealing with misinformation (Butcher, 2021).

Passing on the information that vaccines are safe is a new challenge in managing communication on pandemic issues, therefore, the present study ${ }^{12}$ sought to understand the use of social media in building credible and reliable information on the subject. We selected four social media platforms - Facebook, Instagram, Twitter and LinkedIn - and collected all utterances concerning vaccination posted by the European Commission $(E C / E U)$, the European Medicines Agency (EMA), the World Health Organization Regional Office for Europe (WHO/ROE), the European Centre for Disease Prevention and Control (ECDPC), Representation of the European Commission in Portugal (REC/PT), Portuguese Government (Gov/PT), Portuguese Directorate-General of Health (DGS), and Portuguese National Health Service (SNS) during one month, starting from the authorization of the first vaccine in the EU (21st December 2020).

The relevance of digital communication in the current media and information landscape is undeniable (Neuman, 2016; Reyna et al, 2018), so the official sources are increasingly betting on this type of communication, through the promotion of their websites and their pages in digital social networks that are more active and closer to the public. The choice of social media (Facebook, Twitter, Instagram and LinkedIn) was based on an exploratory analysis of the platforms most used and promoted by the elected official authorities. According to data presented by Statecounter/Global Stats ${ }^{13}$, for the period between January 2020 and January 2021, Facebook had a usage of around 77\%, followed by Pinterest $(10.3 \%)$, Twitter $(7.2 \%)$ and Instagram $(2.1 \%)$. With a view to large-scale communication, the sources analyzed used the three social media platforms of mainstream interaction (Facebook, Twitter and Instagram), to which was added LinkedIn, a professional platform with almost 740 million members (166 million in Europe $)^{14}$, showing signs of growth, both in terms of access and in terms of interaction.

12 This is part of a wider project that aims to study the communication about Covid-19 vaccination through a twofold analysis: the media coverage of Covid-19 vaccination in the Portuguese news media and the strategic communication of official news sources, both Portuguese and European.

13 https://gs.statcounter.com/social-media-stats/all/europe, accessed on February 14th 2021.

14 https://news.linkedin.com/about-us\#Statistics, accessed on February 14th 2021. 
Thematic dossier- International Relations and Social Networks (July 2021), pp. 157-179

The Covid-19 vaccination agenda. European and Portuguese official sources' performance

in Facebook, Instagram, Twitter and Linkedin

Clara Almeida Santos, Olga Estrela Magalhães, Catarina Duff Burnay, Rita Araújo

Table 1: Number of followers of the official sources on each platform in January 2021 (M-Million; m-thousand)

\begin{tabular}{|c|c|c|c|c|}
\hline & Facebook & Instagram & Twitter & Linkedln \\
\hline European Commission & $1.2 \mathrm{M}$ & $557 m$ & $1.4 \mathrm{M}$ & $1 \mathrm{M}$ \\
\hline $\begin{array}{l}\text { WHO Regional Office for } \\
\text { Europe }\end{array}$ & $611 \mathrm{~m}$ & $81 \mathrm{~m}$ & $155 \mathrm{~m}$ & $\begin{array}{c}6.3 \mathrm{~m} \text { (no } \\
\text { publications) }\end{array}$ \\
\hline $\begin{array}{l}\text { European Centre for Disease } \\
\text { Prevention and Control }\end{array}$ & $243 m$ & $\mathrm{~N} / \mathrm{a}$ & $75,1 \mathrm{~m}$ & $32 \mathrm{~m}$ \\
\hline European Medicines Agency & $\mathrm{N} / \mathrm{a}$ & $\mathrm{N} / \mathrm{a}$ & $68,9 \mathrm{~m}$ & $154.2 \mathrm{~m}$ \\
\hline Portuguese Gouvernment & $77.4 \mathrm{~m}$ & $71.8 \mathrm{~m}$ & $166.3 \mathrm{~m}$ & $5.3 m$ \\
\hline $\begin{array}{l}\text { Portuguese Directorate- } \\
\text { General of Health }\end{array}$ & $701.4 \mathrm{~m}$ & $22.5 \mathrm{~m}$ & $47 m$ & $\begin{array}{c}2.6 \mathrm{~m} \text { (no } \\
\text { publications) }\end{array}$ \\
\hline Infarmed, IP & $16.5 \mathrm{~m}$ & $\mathrm{~N} / \mathrm{a}$ & $6.3 m$ & $42.3 m$ \\
\hline $\begin{array}{l}\text { Portuguese National Health } \\
\text { Service }\end{array}$ & $266.3 m$ & $173 m$ & $30 \mathrm{~m}$ & $\mathrm{~N} / \mathrm{a}$ \\
\hline $\begin{array}{l}\text { European Commission - } \\
\text { Portuguese Representation }\end{array}$ & $61.4 \mathrm{~m}$ & $25,2 m$ & $23.4 \mathrm{~m}$ & $\mathrm{~N} / \mathrm{a}$ \\
\hline
\end{tabular}

Source: Prepared by the authors

\section{Case study and data analysis}

The corpus consists of 719 posts corresponding to all utterances on the subject of or referring "vaccination" published between December 21st, 2020, and January 21st, 2021, by verified public pages of the above-mentioned official sources on the selected social media platforms ${ }^{15}$.

15 After coding and using the application Statistical Package for Social Sciences (SPSS) the posts were submitted to content analysis using the following variables:

V1. Social Media [Indicates the platform where the post was published]

1.Facebook

2.Instagram

3.Twitter

4.LinkedIn

V2. Official source [Indicates who authored the post]

1. European Commission

2. WHO Regional Office for Europe

3. European Centre for Disease Prevention and Control

4. Portuguese Government

5. Portuguese Directorate-General of Health

6. Infarmed, IP

7. Portuguese National Health Service

8. Representation of the European Commission in Portugal

V3 and V4. Multimediality [Indicates the media formats used in the post, up to 2]

1. Text

2. Photo

3. Photo gallery (more than one photo)

4. Video 
5. Audio

6. Graphic

7. Poster

8. Animation

9. Live

10. Infographics

V5. Hypertext [Describes the landing pages or platforms to where the post links to]

1. Developed information in sites (other than the source's)

2. Further information in the platform where the post was published

3. Other national sources (sites)

4. Other international sources (sites)

5. Other social media

6. Source's site

7. Repost [when the post is simple repost with no other format (V3 or V4)

8. Other resources

V6. Hashtags [string variable that collects all the hashtags used in the post]

V7. Geography [Indicates the geographical approach]

1. National

2. International

3. Both

V8. Frame [Analyses the post's discourse aiming to assess the motivation/intention of the post and post's author]

1. Informative

2. Pedagogical

3. Persuasive

4. Defensive

5. Positive

6. Other

V9. Theme [Indicates the main theme of the post; the list of potential themes was adapted from a project on health communication] (Lopes et al, 2013, Araújo, 2016).

1. Research development

2. Ribonucleic acid

3. Clinical trials

4. Vaccine validation

5. Vaccine administration

6. Difficulties in administration

7. Adverse effects

8. Deadlines

9. Priority groups

10. Distribution

11. Storage

12. Deadline failure

13. Distribution problems

14. Storage problems

15. National portraits

16. International portraits

17. Political decisions

18. Health officers' decisions

19. Political reactions

20. Economy

21. Protests

22. Vaccine security

23. Professional situations

24. European success

25. Generic approach

26. Authorization

27. Technical/scientific information

28. Acknowledgment

29. Fact check

V10. Actor [Indicates the main actor/s in the post; if the post is a repost, the actor is the author of the original post]

1. Source's official representative

2. Expert

3. Celebrity

4. Politician

5. Citizen(s) 
The posts were collected in the four platforms during the period of analysis (from the 21 st to the December 2020 to the 21st of January 2021). The objective was to gather all the posts produced by the sources that are being studied.

We computed the data using SPPS (Statistical Package for Social Sciences). Then, we run a descriptive analysis of all variables, crossing results when considered interesting for getting some insight.

\section{Findings and discussion}

From all sources analyzed, the most prolific was the Portuguese National Health Service, authoring $31 \%$ of all posts, followed by the EC, with $24 \%$ of the posts.

Table 2. Number of publications by source

\begin{tabular}{lc}
\hline Source & Frequency \\
\hline European Commission & 172 \\
\hline WHO Regional Office for Europe & 33 \\
\hline European Centre for Disease Prevention and Control & 67 \\
\hline Portuguese Gouvernment & 36 \\
\hline Portuguese Directorate-General of Health & 17 \\
\hline Infarmed, IP & 21 \\
\hline Portuguese National Health Service & 223 \\
\hline European Commission's Portuguese Representation & 99 \\
\hline European Medicines Agency & 51 \\
\hline
\end{tabular}

Source: Prepared by the authors

Twitter was the most used social media platform with $56,9 \%$ of all posts, followed by Facebook with less than all the amount of posts (22.5\%). All sources (except the Portuguese

Directorate-General of Health) used more Twitter than the other social media (Table 3).

6. Several (when more than one of the other actors in this list)

7. Health professional(s)

8. Other official source

9. Other 
Thematic dossier- International Relations and Social Networks (July 2021), pp. 157-179 The Covid-19 vaccination agenda. European and Portuguese official sources' performance

Table 3: social media used by each source

\begin{tabular}{|l|c|c|c|c|}
\hline & \multicolumn{4}{|c|}{ Social Media } \\
\hline Source & Facebook & Instagram & Twitter & Linkedln \\
\hline European Commission & 34 & 28 & 88 & 22 \\
\hline WHO Regional Office for Europe & 6 & 3 & 24 & 0 \\
\hline European Centre for Disease Prevention and Control & 8 & 0 & 57 & 2 \\
\hline Portuguese Gouvernment & 6 & 5 & 25 & 0 \\
\hline Portuguese Directorate-General of Health & 8 & 4 & 5 & 0 \\
\hline Infarmed, IP & 5 & 0 & 9 & 7 \\
\hline Portuguese National Health Service & 74 & 56 & 93 & 0 \\
\hline European Commission's Portuguese Representation & 21 & 18 & 60 & 0 \\
\hline European Medicines Agency & 0 & 0 & 48 & 3 \\
\hline Total & 162 & 114 & 409 & 34 \\
\hline
\end{tabular}

Source: Prepared by the authors

During the time period that was analyzed, the days with more posts (more than $5 \%$ of the total) coincide with: 1) the authorization of the first vaccine in the European Union (21st December 2020); 2) a public meeting held by the EMA about the vaccine (8th January 2021); 3) the beginning of vaccination in every member state of the EU (27th December); 4) the day before the beginning of vaccination in the EU (26th December $2020)$; 5) the authorization of the second vaccine (6th January 2021) (Table 4 and Graphic 1).

Table 4: Number of posts per date

\begin{tabular}{|c|c|c|c|c|c|}
\hline Date & Frequency & Percentage & Date & Frequency & Percentage \\
\hline 21.12 .2020 & 72 & 10,0 & 06.01 .2021 & 38 & 5,3 \\
\hline 22.12.2020 & 24 & 3,3 & 07.01 .2021 & 30 & 4,2 \\
\hline 23.12.2020 & 15 & 2,1 & 08.01 .2021 & 68 & 9,5 \\
\hline 24.12.2020 & 14 & 1,9 & 09.01 .2021 & 14 & 1,9 \\
\hline 25.12.2020 & 4 & 0,6 & 10.01.2021 & 15 & 2,1 \\
\hline 26.12.2020 & 49 & 6,8 & 11.01 .2021 & 8 & 1,1 \\
\hline 27.12 .2020 & 53 & 7,4 & 12.01 .2021 & 17 & 2,4 \\
\hline 28.12 .2020 & 28 & 3,9 & 13.01 .2021 & 30 & 4,2 \\
\hline 29.12.2020 & 26 & 3,6 & 14.01 .2021 & 15 & 2,1 \\
\hline 30.12 .2020 & 14 & 1,9 & 15.01 .2021 & 27 & 3,8 \\
\hline 31.12 .2020 & 7 & 1,0 & 16.01 .2021 & 21 & 2,9 \\
\hline 01.01 .2021 & 4 & 0,6 & 17.01 .2021 & 13 & 1,8 \\
\hline 02.01 .2021 & 5 & 0,7 & 18.01 .2021 & 13 & 1,8 \\
\hline 03.01 .2021 & 3 & 0,4 & 19.01 .2021 & 35 & 4,9 \\
\hline 04.01 .2021 & 11 & 1,5 & 20.01 .2021 & 17 & 2,4 \\
\hline 05.01 .2021 & 4 & 0,6 & 21.01 .2021 & 25 & 3,5 \\
\hline
\end{tabular}

Source: Prepared by the authors 
Thematic dossier- International Relations and Social Networks (July 2021), pp. 157-179 The Covid-19 vaccination agenda. European and Portuguese official sources' performance

Graphic 1: Number of posts per date

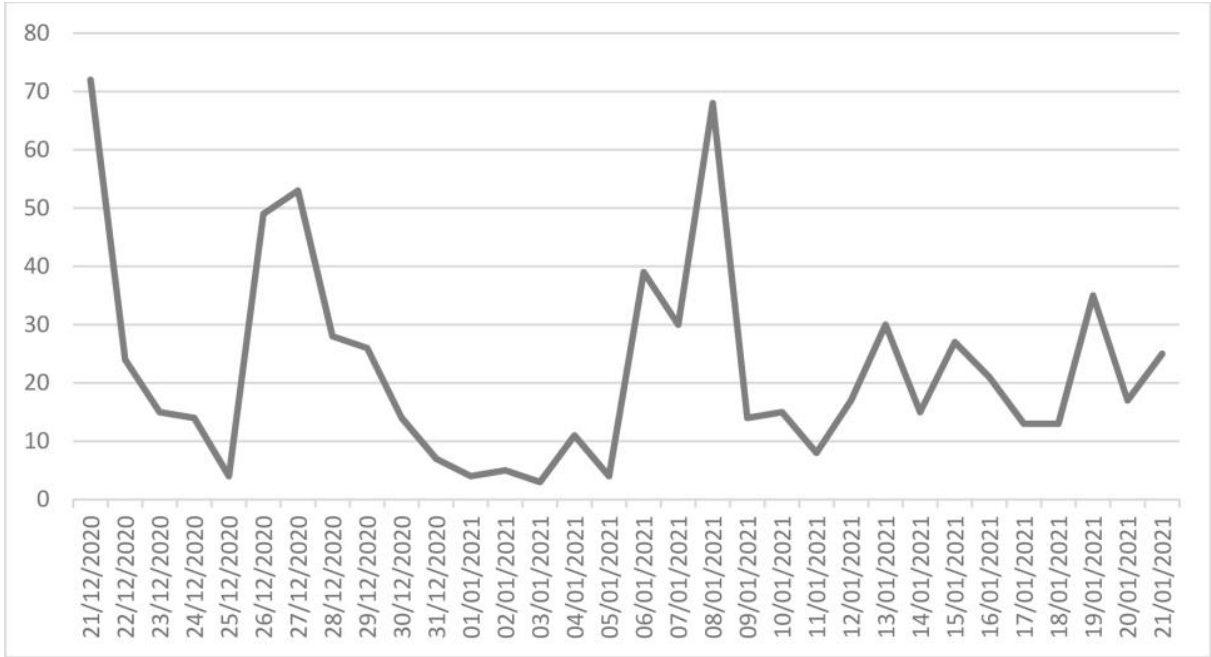

Source: Prepared by the authors

When crossing the date with the theme for those five days, we find that the most prominent themes were "Vaccine administration", "Authorization", "Generic approach" and "Vaccine security" (Table 5).

Table 5: Themes on specific dates

\begin{tabular}{|c|c|c|c|c|c|c|}
\hline \multirow[t]{2}{*}{ Theme } & \multicolumn{6}{|c|}{ Date } \\
\hline & 21.12 .2020 & 27.12 .2020 & 28.12 .2020 & 06.01 .2021 & 08.01 .2021 & Total \\
\hline Research development & 0 & 0 & 0 & 1 & 0 & 1 \\
\hline Ribonucleic acid & 1 & 0 & 0 & 1 & 3 & 5 \\
\hline Clinical trials & 2 & 0 & 0 & 0 & 1 & 3 \\
\hline Validation & 1 & 0 & 0 & 0 & 5 & 6 \\
\hline Vaccine administration & 2 & 38 & 11 & 9 & 16 & 76 \\
\hline Adverse effects & 1 & 0 & 0 & 0 & 0 & 1 \\
\hline Priority groups & 0 & 1 & 0 & 0 & 0 & 1 \\
\hline Distribution & 0 & 3 & 0 & 0 & 0 & 3 \\
\hline International portraits & 0 & 3 & 2 & 0 & 0 & 5 \\
\hline Political decisions & 0 & 0 & 0 & 0 & 3 & 3 \\
\hline Health officers decisions & 0 & 0 & 1 & 0 & 0 & 1 \\
\hline Vaccine security & 15 & 2 & 0 & 0 & 7 & 24 \\
\hline Professional situations & 0 & 0 & 1 & 0 & 1 & 2 \\
\hline European success & 4 & 3 & 0 & 0 & 0 & 7 \\
\hline Generic vaccine & 3 & 2 & 5 & 5 & 26 & 41 \\
\hline Authorization & 41 & 0 & 1 & 22 & 1 & 65 \\
\hline Technical/scientifica information & 1 & 0 & 2 & 0 & 5 & 8 \\
\hline Ackowlegments & 1 & 1 & 5 & 0 & 0 & 7 \\
\hline Total & 72 & 53 & 28 & 38 & 68 & 259 \\
\hline
\end{tabular}

Source: Prepared by the authors 
The posts about "Vaccine administration" focus on the beginning of the vaccination process in every member state of the EU and particularly in Portugal (as far as the Portuguese sources are concerned). The National Health Service has carried out a campaign showing vaccines being inoculated in several institutions outside the capital and main cities. The European sources also used this kind of approach but being less prolific. One interesting remark is the use of the hashtag \#EUVaccinationDays. The theme "Authorization" refers mainly to posts focusing on the announcement of the authorization of the vaccines (Pfizer/BioNTech, on the 21th December 2020, and Moderna on the 6th January 2021). The "Generic approach" theme is registered when the vaccine is mentioned generically, without any specific thematic or when several themes are addressed in the same post, none of them being sufficiently prominent to be identified as "the" theme of the post. "Vaccine security" identifies normally reassuring content about the safeness of the vaccine, thus showing understanding citizens' main concern.

These four themes account for $79.5 \%$ of all themes in the referred dates. If we include all dates (Table 6), we will find that "Vaccine administration" is present in $34.8 \%$ of the posts, followed by "Generic approach" (19.7\%) and "Authorization" (12.2\%). We should also underline the $8.5 \%$ of posts devoted to "Vaccine security", published by European official sources and by the EC Representation in Portugal.

Table 6: Themes

\begin{tabular}{|l|c|c|}
\hline & Frequency & Percentage \\
\hline Research development & 10 & 1,4 \\
\hline RNA & 13 & 1,8 \\
\hline Clinical trials & 7 & 1,0 \\
\hline Validation & 13 & 1,8 \\
\hline Administration & $\mathbf{2 5 0}$ & $\mathbf{3 4 , 8}$ \\
\hline Adverse effects & 1 & 0,1 \\
\hline Priority groups & 10 & 1,4 \\
\hline Distribution & 32 & 4,5 \\
\hline International portraits & 17 & 2,4 \\
\hline Political decisions & 7 & 1,0 \\
\hline Health officers decisions & 4 & 0,6 \\
\hline Political reactions & 1 & 0,1 \\
\hline Economy & 3 & 0,4 \\
\hline Vaccine security & 61 & 8,5 \\
\hline Professional situations & 2 & 0,3 \\
\hline European Success & 18 & 2,5 \\
\hline Generic vaccine & 142 & 19,7 \\
\hline Authorization & $\mathbf{8 8}$ & $\mathbf{1 2 , 2}$ \\
\hline Technical/scientific information & 24 & 3,3 \\
\hline Acknowledgments & 10 & 1,4 \\
\hline Fact check & 619 & 0,8 \\
\hline Total & & 100,0 \\
\hline
\end{tabular}

Source: Prepared by the authors 
As far as multimediality is concerned, the most used format is text, present in nearly $80 \%$ of the posts. The posts that do not present texts are reposts (not identified as having text authored by the official source). Posters, a category that identifies a sort of billboard that uses both photography and typography, and sometimes even illustrations, very similar to advertising signs, account for $28.4 \%$ of all formats used in the posts. Crossing multimediality with sources, we find that the Portuguese National Health Service uses this format in 133 posts (out of 223, representing the presence of this kind of resource in $59.7 \%$ of all posts). The Representation of the European Commission in Portugal also relies on this format in $29.3 \%$ of its posts and the European Commission uses it in $12.8 \%$ of its posts.

It should be noted that the posters used by the Representation of the European Commission in Portugal are often the same used by the European Commission (translated into Portuguese).

Table 7: Multimediality

\begin{tabular}{|l|c|}
\hline Multimediality & Frequency \\
\hline Text & 575 \\
\hline Photo & 48 \\
\hline Photo gallery & 31 \\
\hline Video & 77 \\
\hline Graphis & 1 \\
\hline Poster & 204 \\
\hline Animation & 14 \\
\hline Live & 3 \\
\hline Infographics & 36 \\
\hline
\end{tabular}

Source: Prepared by the authors

Video is used mainly by the European Commission (present in $20.3 \%$ of all posts), being the second most used format by this source (after text) and by its Representation in Portugal (24.2\% of all posts).

Regarding hypertext in the posts, the most frequent is reposting (used in nearly half the posts with hypertext), what relates to the wide use of Twitter and the habit of reposting in this platform. Given this result, we crossed hypertext with the actors (Table 8 ) to find that the reposts are mainly authored by other official sources (namely the ones identified in this article, both national and international) and by the source's official representative. 
Table 8. Hypertext and actors

\begin{tabular}{|c|c|c|c|c|c|c|c|c|}
\hline \multicolumn{9}{|c|}{ Hypertext } \\
\hline & $\begin{array}{l}\text { Developed } \\
\text { information }\end{array}$ & $\begin{array}{c}\text { More information } \\
\text { inside the social } \\
\text { media }\end{array}$ & $\begin{array}{l}\text { Other inter- } \\
\text { national plat- } \\
\text { forms }\end{array}$ & $\begin{array}{l}\text { Other social } \\
\text { media }\end{array}$ & $\begin{array}{l}\text { Source's } \\
\text { official sites }\end{array}$ & $\begin{array}{c}\text { Other } \\
\text { resources }\end{array}$ & Repost & Total \\
\hline $\begin{array}{l}\text { Oficial source's } \\
\text { reresentative }\end{array}$ & 2 & 0 & 1 & 11 & 33 & 2 & 46 & 95 \\
\hline Expert & 0 & 0 & 0 & 1 & 10 & 0 & 2 & 13 \\
\hline Politician & 0 & 0 & 0 & 0 & 0 & 1 & 5 & 6 \\
\hline Citizen(s) & 0 & 0 & 0 & 0 & 3 & 0 & 1 & 4 \\
\hline Other & 0 & 0 & 0 & 0 & 5 & 1 & 1 & 7 \\
\hline Several & 0 & 0 & 6 & 3 & 40 & 0 & 17 & 66 \\
\hline $\begin{array}{l}\text { Health profes- } \\
\text { sionals }\end{array}$ & 0 & 0 & 2 & 0 & 19 & 0 & 14 & 35 \\
\hline $\begin{array}{l}\text { Other official } \\
\text { source }\end{array}$ & 1 & 0 & 10 & 7 & 12 & 0 & 70 & 100 \\
\hline Total & 3 & 2 & 19 & 22 & 122 & 4 & 156 & 326 \\
\hline
\end{tabular}

Source: Prepared by the authors

Linking to the source's official sites is done in $37.4 \%$ of all posts where we can find links. It is interesting to notice that hypertext is present in $60.8 \%$ of all posts (not in all of them actors can be identified). The sources that use this feature the most are the European Center for Disease Control and Prevention and Infarmed, IP (only one of their posts does not have hypertext). The Portuguese Government uses hypertext in more than $90 \%$ of its posts (Table 9 ).

Table 9: Hypertext and sources

\begin{tabular}{|c|c|c|c|}
\hline & Frequency & Hypertext & Percentage of hypertext usage \\
\hline European Commission & 172 & 80 & 46,5 \\
\hline WHO Regional Office for Europe & 33 & 28 & 84,8 \\
\hline $\begin{array}{l}\text { European Centre for Disease } \\
\text { Prevention and Control }\end{array}$ & 67 & 66 & 98,5 \\
\hline Portuguese Gouvernment & 36 & 34 & 94,4 \\
\hline $\begin{array}{l}\text { Portuguese Directorate-General } \\
\text { of Health }\end{array}$ & 17 & 12 & 70,6 \\
\hline Infarmed, IP & 21 & 20 & 95,2 \\
\hline $\begin{array}{l}\text { Portuguese National Health Ser- } \\
\text { vice }\end{array}$ & 223 & 123 & 55,2 \\
\hline $\begin{array}{l}\text { European Commission's Portu- } \\
\text { guese Representation }\end{array}$ & 99 & 49 & 49,5 \\
\hline European Medicines Agency & 51 & 25 & 49,0 \\
\hline Total & 719 & & \\
\hline
\end{tabular}

Source: Prepared by the authors

Many posts refer several actors simultaneously, namely UE citizens and health professionals, what occurs frequently when the theme is the administration of the vaccine. When adding up official sources and representatives of the source that authors the publication or other official sources, official sources prevail (Table 10). 
Thematic dossier- International Relations and Social Networks (July 2021), pp. 157-179

The Covid-19 vaccination agenda. European and Portuguese official sources' performance

Table 10. Actors

\begin{tabular}{|l|c|c|}
\hline \multicolumn{1}{|l}{ Actor } & & \\
& Frequency & Percentage \\
\hline Official source's representative & 113 & 15,7 \\
\hline Expert & 19 & 2,6 \\
\hline Politician & 6 & 0,8 \\
\hline Citizen(s) & 20 & 2,8 \\
\hline Other & 10 & 1,4 \\
\hline Several & 198 & 27,5 \\
\hline Health professional(s) & 47 & 6,5 \\
\hline Other official source & 111 & 15,4 \\
\hline Total & 524 & 72,9 \\
\hline
\end{tabular}

Source: Prepared by the authors

Regarding the discursive frame of the messages, the results show that the majority of the posts (55.4\%) are informative, conveying uncluttered and objective information. The themes with more informative frame are "Vaccine administration" (43.7\% of all posts labeled as informative) and when the vaccine is generically approached (in $17.1 \%$ of the informative posts) (Table 11). These are also the themes where a more positive discourse is constructed. A pedagogical approach is used when posting about the vaccine safety and about several aspects of the vaccine and vaccination process (Generic approach).

Table 11: Themes and message framing

\begin{tabular}{|l|c|c|c|c|c|c|c|}
\hline & Informative & Pedagogical & Persuasive & Defensive & Positive & Other & Total \\
\hline Vaccine Developement & 5 & 1 & 0 & 0 & 4 & 0 & 10 \\
\hline RNA & 5 & 8 & 0 & 0 & 0 & 0 & 13 \\
\hline Clinical trials & 3 & 1 & 0 & 0 & 3 & 0 & 7 \\
\hline Validation & 10 & 1 & 0 & 0 & 2 & 0 & 13 \\
\hline Administration & 174 & 0 & 14 & 0 & 62 & 0 & 250 \\
\hline Adverse effects & 0 & 0 & 1 & 0 & 0 & 0 & 1 \\
\hline Priority groups & 8 & 0 & 0 & 0 & 2 & 0 & 10 \\
\hline Distribution & 24 & 0 & 0 & 0 & 8 & 0 & 32 \\
\hline International portraits & 1 & 0 & 10 & 0 & 6 & 0 & 17 \\
\hline Political decisions & 3 & 0 & 0 & 0 & 4 & 0 & 7 \\
\hline Health authorities decisions & 3 & 0 & 0 & 0 & 1 & 0 & 4 \\
\hline Political reactions & 1 & 0 & 0 & 0 & 0 & 0 & 1 \\
\hline Economy & 2 & 0 & 0 & 0 & 1 & 0 & 3 \\
\hline Vaccine safety & 23 & 18 & 9 & 5 & 6 & 0 & 61 \\
\hline Professional situations & 0 & 1 & 0 & 0 & 1 & 0 & 2 \\
\hline European success & 1 & 0 & 0 & 0 & 17 & 0 & 18 \\
\hline Generic vaccine & 68 & 16 & 8 & 0 & 49 & 1 & 142 \\
\hline Authorization & 49 & 3 & 1 & 0 & 44 & 0 & 88 \\
\hline Technical/scientific information & 21 & 3 & 0 & 0 & 0 & 0 & 24 \\
\hline Acknowlegments & 1 & 0 & 0 & 0 & 9 & 0 & 10 \\
\hline Fact check & 5 & 1 & 0 & 0 & 0 & 0 & 6 \\
\hline Total & 53 & 43 & 5 & 219 & 1 & 719 \\
\hline
\end{tabular}

Source: Prepared by the authors 
In absolute numbers, the most positive source is the European Commission, followed by the Portuguese National Health Service, which is the most informative source (Table 12).

Table 12: Sources and discursive framework

\begin{tabular}{|l|c|c|c|c|c|c|c|}
\hline \multicolumn{1}{|c|}{ Source/Frame } & Informative & Pedagogical & Persuasive & Defensive & Positive & Other & Total \\
\hline European Commission & 53 & 26 & 18 & 0 & 74 & 1 & 172 \\
\hline $\begin{array}{l}\text { WHO Regional Office for Europe } \\
\text { European Centre for Disease }\end{array}$ & 13 & 9 & 0 & 0 & 11 & 0 & 33 \\
\hline $\begin{array}{l}\text { Prevention and Control } \\
\text { Portuguese Gouvernment }\end{array}$ & 37 & 2 & 2 & 4 & 22 & 0 & 67 \\
\hline $\begin{array}{l}\text { Portuguese Directorate-General } \\
\text { of Health }\end{array}$ & 12 & 0 & 2 & 0 & 3 & 0 & 17 \\
\hline Infarmed, IP & 18 & 0 & 0 & 0 & 3 & 0 & 21 \\
\hline $\begin{array}{l}\text { Portuguese National Health Ser- } \\
\text { vice }\end{array}$ & 180 & 1 & 8 & 0 & 34 & 0 & 223 \\
\hline $\begin{array}{l}\text { European Commission's Portu- } \\
\text { guese Representation }\end{array}$ & 25 & 5 & 7 & 1 & 61 & 0 & 99 \\
\hline $\begin{array}{l}\text { European Medicines Agency } \\
\text { Total }\end{array}$ & 32 & 10 & 4 & 0 & 5 & 0 & 51 \\
\hline
\end{tabular}

Source: Prepared by the authors

When weighing the frame used with the total amount of posts, we find that the Portuguese National Health Service is still the source with a higher percentage of informative posts $(80.7 \%)$. The more pedagogical is the European Medicines Agency (31.3\% of the posts), followed closely by the WHO Regional Office for Europe $(27.3 \%)$. The persuasive frame is more used by the European Commission (10.5\% of its posts) and by the European Commission's Representation in Portugal (7.1\%). The defensive mode is practically only activated by the European Center for Disease Prevention and Control (6\% of its publications). The most positive source considering weight of this frame on the total of publications is the European Commission's Representation in Portugal $(61.8 \%)$, followed by the European Commission (43\%).

Crossing frames with the social media platforms, Facebook is where the highest percentage of informative posts is published. In all platforms, informative and positive framing account a very high percentage of the total of posts ( $88 \%$ on Facebook; $89 \%$ on Instagram; $84 \%$ on Twitter and $85 \%$ on LinkedIn) (Table 13 ).

Table 13: Message framing in social media

\begin{tabular}{|c|c|c|c|c|c|c|c|c|c|c|}
\hline \multirow{2}{*}{$\begin{array}{l}\text { Social media } \\
\text { Frame }\end{array}$} & \multicolumn{2}{|c|}{ Facebook } & \multicolumn{2}{|c|}{ Instagram } & \multicolumn{2}{|c|}{ Twitter } & \multicolumn{2}{|c|}{ Linkedln } & \multicolumn{2}{|c|}{ Total } \\
\hline & $\mathrm{N}$ & $\%$ & $\mathrm{~N}$ & $\%$ & $\mathrm{~N}$ & $\%$ & $\mathrm{~N}$ & $\%$ & $\mathrm{~N}$ & $\%$ \\
\hline Informative & 99 & 61 & 61 & 54 & 224 & 55 & 14 & 41 & 398 & 55 \\
\hline Pedagogical & 9 & 6 & 2 & 2 & 38 & 9 & 4 & 12 & 53 & 7 \\
\hline Persuasive & 10 & 6 & 9 & 8 & 23 & 6 & 1 & 3 & 43 & 6 \\
\hline Defensive & 0 & 0 & 1 & 1 & 4 & 1 & 0 & 0 & 5 & 0,7 \\
\hline Positive & 44 & 27 & 40 & 35 & 120 & 29 & 15 & 44 & 219 & 30 \\
\hline Other & 0 & 0 & 1 & 1 & 0 & 0 & 0 & 0 & 1 & 0 \\
\hline Total & 162 & 100 & 114 & 100 & 409 & 100 & 34 & 100 & 719 & 100 \\
\hline
\end{tabular}

Source: Prepared by the authors 


\section{Final remarks}

The results show that Portuguese and European official sources (governmental and health authorities) are using social media to convey information about Covid-19 vaccination. In average, all sources together published 24 posts per day during the month of the study. The most prolific source in this study, the Portuguese National Health Service, published, in average, 7.4 posts each day.

Twitter is the platform where more posts are published by 8 out of 9 sources analyzed, even though it is not the one with the highest number of followers. The exception is the Portuguese General-Directorate of Health, whose number of total posts is scarce -17 publications, representing $2.4 \%$ of the corpus. Although this source has played a very prominent role since the beginning of the pandemics in terms of communication, the vaccination campaign seems to have been delegated to the National Health Service. Adding up all followers of the official pages of the sources in the digital networks in this research (data accessed in January 2021), Facebook leads with 3.4 million, followed by Twitter with 1.9 million, LinkedIn with 1.2 million and Instagram with 931 thousand. A possible explanation for the $56,9 \%$ of all posts published on Twitter is that this platform is attended by many journalists and is claimed to be the preferred professional tool/source as far as social media are concerned (Parmelee, 2013). This possibility brings us back to a sophisticated and digitalized version of Lazarsfeld and Katz's theory of the "two-step flow of communication": using Twitter (and other social media), official sources might reach journalists in an unconventional, uncommitted way; sources are directly speaking to the general public knowing that the message will also target journalists. The apparently unmediated content gains the potential to be mediated through journalists playing their role as opinion leaders. In this version of the two-step flow theory, social media are in the beginning of the chain and legacy media on the other end.

This communication strategy also contributes to create a buzz marketing effect. The positive framing of the vaccine campaign (registered in $30.5 \%$ of all posts), especially in what concerns the European accomplishment, the authorization and the administration process starting on the same day in every member state, contributes to the emotional trigger that buzz marketing relies on. The effect depends on repetition and redundancy: administration and authorization in the EU account for $47 \%$ of the themes in all posts that constitute the corpus. Other explanation for the expressive usage of Twitter has to do with the platform's posting characteristics, privileging shorter and more frequent posting. Twitter shows, more than the other platforms, an articulation between European official sources with many cross referral and tagging, especially between the European Medicines Agency and the European Commission. Instagram, in turn, relies mainly in images and official sources use that specificity to channel the more promotional format and language, using the "poster" messages. The sources strategy takes into consideration the specific potential of each platform, and efficiently adjusts the formats. There seems to be some contempt regarding LinkedIn (with a considerable number of followers in some sources' page while other sources do not even have a page). Given the nature of this social network it could be an effective space to disseminate authoritative information, nourishing the "two-step flow". 
With the death and disease tolls, after the lockdowns and under the shadow of a new wave of Covid-19, vaccination represents hope (a "light at the end of the tunnel", as was constantly repeated) and that hope was capitalized by official sources (mainly governmental, both European and Portuguese) also with strong political intentions. The momentum, especially in what concerns the authorization of the vaccine and the beginning of the vaccination process, was favorable to the appraisal of the European ideals of solidarity, working for common goals and attaining them. The European Commission and its Representation in Portugal are the most positive sources, reinforcing the importance of the European project in an adversarial context. This positiveness is enhanced by using abundantly the hashtags \#EUVaccinationDays, \#StrongerTogether and \#UnitedAgainstCoronavirus.

Political twist and uplifting do not mean that the main concerns about vaccinations assuring its security and providing authoritative information to mitigate information disorders - were not met though the communication practices in social media. In more than one third of the posts there are links developed information on the source's official websites. And it should be noted that informative framing is the most common one (in $55.4 \%$ of the posts). The strategy to convey authoritative information from reliable sources is thus enforced. Yet, it seems that a much broader task of disseminating this kind of information is entrusted to social media themselves, through several initiatives that Twitter, Facebook, Instagram and also TikTok have agreed to engage in.

This case study shows the importance of social media analysis in the context of the Covid19 vaccination. It will be used as an exploratory study on official source's digital communication practices during the vaccination campaign in the EU.

\section{References}

Arif, N. Al-Jefri, M., Bizzi, I. H., Perano, G. B.,Goldman, M., Haq, I., Chua, K. L., Mengozzi, M. Neunez, M., Smith, H., \& Ghezzi, P. (2018). Fake News or Weak Science? Visibility and Characterization of Antivaccine Webpages Returned by Google in Different Languages and Countries. Frontiers in Immunology, 9, 1215.

Berkman, N. D., Davis, T. C., \& McCormack, L. (2010). Health Literacy: What Is It? Journal of Health Communication, 15 (2), 9-19.

Biasio, L. R., Bonaccorsi, G., Lorini, C., \& Pecorelli, S. (2020). Assessing COVID-19 vaccine literacy: a preliminary online survey. Human Vaccines \& Immunotherapeutics [2020, January 20]. Available from https://doi.org/10.1080/21645515.2020.1829315.

Butcher, P. (2021). COVID-19 as a turning point in the fight against disinformation. Nature Electronics, 4, pp. 7-9. [2020, January 20]. Available from https://www.nature.com/articles/s41928-020-00532-2.

Cardoso, G., Paisana, M. \& Pinto-Martinho, A. (2020). Reuters Digital News Report 2020

- Portugal. Obercom. [2020, January 21]. Available from https://obercom.pt/reutersinstitute-digital-news-report-2020-portugal. 
Cinelli, M., Quattrociocchi, W., Galeazzi, A. Valensise, C. M., Brugnoli, E., Schmidt, A. L., Zola, P., Zollo, F., \& Scala, A. (2020). The COVID-19 social media infodemic. Nature Sci Rep 10, 16598. [2020, January 20]. Available from https://www.nature.com/articles/s41598-020-73510-5.

Fielding, J. (2020). Good communication will help beat COVID-19. The Hill. [2020, January 20]. Available from https://thehill.com/opinion/healthcare/490410-goodcommunications-will-help-beat-covid-19.

Finset, A., Bosworth H., Butow P., Gulbrandsen, P., Hulsman, R. L., Pieterse, A. H., Street, R., Tschoetschel, R., \& Van Weert, J. (2020) Effective health communication - a key factor in fighting the COVID-19 pandemic. Patient Education and Counseling, 103(5): 873-876.

Ireton, C., \& Posetti, J. (2018). Journalism, fake news \& disinformation: handbook for journalism education and training. Paris: UNESCO.

Ishikawa, H. \& Kiuchi, T. (2010). Health literacy and Health Communication. Biopsycho Social Medicine, 4(18), 1-5.

Knobler, S., Mahmoud, A., Lemon, S., Mack,A., Sivitz, L., \& Oberholtzer, K. (Eds.) (2004). Learning from SARS: Preparing for the Next Disease Outbreak: Workshop Summary. Washington: National Academies Press. [2020, December 18]. Available from https://www.ncbi.nlm.nih.gov/books/NBK92479.

Jeyanathan, M., Afkhami, S., Smaill, F., Miller, M. S., Lichty, B. D., \& Xing, Z. (2020). Immunological considerations for COVID-19 vaccine strategies. Nature Review Immunology, 20, 615-632.

Magalhães, O. E. (2020). Investigação Médica na Imprensa Portuguesa - diagnóstico de recomendações terapêuticas. Braga: Universidade do Minho.

Magro, M. (2012). A Review of Social Media Use in E-Government. Administrative Sciences 2, 148-161.

Neumann-Böhme, S., Varghese, N. E., Sabat, I., Barros, P. P., Brouwer, W. B. F., van Exel, J., Schreyögg, J., \& Stargardt, T. (2020). Once we have it, will we use it? A European survey on willingness to be vaccinated against COVID-19. European Journal Of Health Economics, 21(7), 977-982.

Neuman, W. R. (2016). The Digital Difference: Media Technology and the Theory of Communication Effects. Harvard University Press.

Newman, N., Fletcher, R., Schulz, A., Andı, S., \& Nielsen, R. K. (2020). Reuters Institute Digital News Report 2020, Reuters Institute for the Study of Journalism.

Nunziato, D.C. (2020). Misinformation Mayhem: social media plataforms' efforts to combat medical and political misinformation. GW Law Faculty Publications \& Other Works. [2020, January 16]. Available from https://scholarship.law.gwu.edu/faculty publications/1502.

Nyhan, B., Reifler, J., Richey, S., \& Freed, G. L. (2014). Effective Messages in Vaccine Promotion: A Randomized Trial. Pedriatics, 2013-2365. 
Oyeyemi, S., Gabarron, E., \& Wynn, R., (2014). Ebola, Twitter, and misinformation: a dangerous combination. British Medical Journal, 349. [2020, December 29]. Available from https://www.bmj.com/content/349/bmj.g6178.

Paakkari, L., \& Okan, O. (2020). COVID-19: Health Literacy is an underestimated problem. The Lancet, 5(5), 249-250.

Paasche-Orlow, M.K., \& Wolf, M.S. (2010). Promoting Health Literacy Research to Reduce Health Disparities. Journal of Health Communication, 15 (2), 34-41.

Parker, R. \& Ratzan. S. C. (2010). Health Literacy: A Second Decade of Distinction for Americans. Journal of Health Communication, 15 (2), 20-33.

Parmelee, J. H. (2013). Political journalists and Twitter: Influences on norms and practices. Journal of Media Practice, 14(4), 291-305.

Pennycook, G., McPethres, J., Zhang, Y., Lu, J.G. \& Rand, G. (2020). Fighting COVID-19 misinformation on social media: experimental evidence for a scalable accuracy-nudge intervention. Psychological Science, 31(7), 770-780.

Radu, R. (2020). Fighting the 'Infodemic': legal responses to Covid-19 disinformation. Social Media + Society, 6(3), 1-4.

Reyna, J., Hanham, J. \& Meier, P. (2018). The Internet explosion, digital media principles and implications to communicate effectively in the digital space. E-Learning and Digital Media, 15(1), 36-52.

Rudd, R. E., Rosenfeld, L., Simonds, V. W. (2012). Health Literacy: A New Area of Research with Links to Communication. Atlantic Journal of Communication, 20(1), 1630.

Santos, C. A., Magalhães, C., Magalhães, J., Moura, I., Costa, M., \& Rosa, M. (2021). Syndemic and therapy. Social media strategies to fight information disorder during Covid19 era. Cosmovisión de la comunicação en redes sociales en la era postdigital. Madrid: McGraw-Hill/Interamericana de España, S.L., 1235-1255.

Schiavo, R. (2020). Vaccine communication in the age of COVID-19: Getting ready for an information war. Journal of Communication in Healthcare, 13(2), 73-75.

Singer, M. (2009). Introduction to Syndemics. A Critical Systems Approach to Public and Community Health. San Francisco: John Wileys and Sons.

Tsao, S.-F., Chen, H., Tisseverasinghe, T., Yang, Y., Li, L. \& Butt, Z.A. (2021). What social media told us in the time of COVID-19: a scoping review. Lancet Digital Health. [30 de dezembro de 2020]. Disponível em

https://www.thelancet.com/journals/landig/article/PIIS2589-7500(20)30315-0/fulltext.

Vanderpool, R.C., Gaysynsky, A., \& Sylvia Chou, W.Y. (2020). Using a Global Pandemic as a Teachable Moment to Promote Vaccine Literacy and Build Resilience to Misinformation. Am J Public Health, 110(S3), 284-285.

Vasconcellos-Silva, P.R., \& Castiel, L.D. (2020). COVID-19, fake news, and the sleep of communicative reason producing monsters: the narrative of risks and the risks of 
narratives. Cadernos de Saúde Pública, 36(7). [29 de dezembro de 2020]. Disponível em https://pubmed.ncbi.nlm.nih.gov/32725084.

Vicario, M., Bessi, A., Zollo, F., Petroni, F., Scala, A., Caldarelli, G., Stanley, E., \& Quattrociocchi, W., (2016). The spreading of misinformation online. Proceedings of the National Academy of Sciences of the United States of America, 113, 554-559.

Wardle, C., Derakhshan, H. (2017). Information Disorder. Strasbourg: Council of Europe. Zarcadoolas, C., Pleasant, A. F., \& Greer, D. S. (2006). Advancing Health Literacy. A Framework for Understanding and Action. San Francisco: Jossey-Bass.

Zarocostas, J. (2020). How to fight an infodemic. The Lancet, 395 (10225), 676. 